\section{(2) OPEN ACCESS}

\title{
Modelling the expected impact of cigarette tax and price increases under Vietnam's excise tax law 2015- 2020
}

\author{
Mark Goodchild (1) , ${ }^{1}$ Le Thi Thu, ${ }^{2}$ Dao The Son, ${ }^{3}$ Lam Nguyen Tuan, ${ }^{4}$ Robert Totanes, ${ }^{1}$ \\ Jeremias Paul, ${ }^{1}$ Kidong Park ${ }^{4}$
}

${ }^{1}$ Health Promotion Department, World Health Organization, Geneva, Switzerland ${ }^{2}$ HealthBridge Foundation of Canada, Hanoi, Vietnam

${ }^{3}$ Thuongmai University, Ha Noi, Vietnam

${ }^{4}$ World Health Organization Country Office for Viet Nam, Hanoi, Vietnam

\section{Correspondence to} Mark Goodchild, World Health Organization, Geneva, Switzerland; goodchildm@who.int

Received 12 May 2020 Revised 17 July 2020 Accepted 5 August 2020
D) Check for updates

(C) Author(s) (or their employer(s)) 2020. Re-use permitted under CC BY-NC. No commercial re-use. See rights and permissions. Published by BMJ.

To cite: Goodchild M, Thu LT, The Son D, et al. Tob Control Epub ahead of print: [please include Day Month Year]. doi:10.1136/

tobaccocontrol-2020-055920

\section{ABSTRACT}

Background Vietnam's national tobacco control strategy aims to reduce the rate of smoking among male adults from $45 \%$ in 2015 to $39 \%$ by 2020 . The aim of this paper is to assess what contribution cigarette tax increases under Vietnam's current excise tax plan can be expected to make to this target, and to discuss what additional measures might be implemented accordingly.

Methods This study uses a mix of administrative datasets and predictive modelling techniques to assess the expected impact of tax and price increases on cigarette consumption, tobacco tax revenues and the rate of smoking between 2015 and 2020.

Findings The average retail price of cigarettes is estimated to have increased by $16 \%$ (sensitivity analysis: 14\%-18\%) in inflation-adjusted terms between 2015 and 2020 , while cigarette consumption is projected to decrease by $5.1 \%(4.5 \%-5.5 \%)$. The rate of smoking among males is projected to decrease to $42.8 \%$ $(42.1 \%-43.6 \%)$ compared with the target of $39 \%$. Total tax revenues from cigarettes are projected to increase by $21 \%(19 \%-23 \%)$, reflecting an extra $₫ 3300$ billion in inflation-adjusted revenues for the government.

Conclusion The current excise tax law is expected to have only a modest impact on the rate of smoking in Vietnam, though it has generated tax revenues. If Vietnam is to achieve its tobacco control targets, the government should implement a mixed excise system with a high-specific component to promote public health by raising the price of cigarettes more significantly.

\section{INTRODUCTION}

The government of Vietnam has recognised the harm caused by tobacco products and committed to reducing tobacco consumption. In 2000, the government adopted a national tobacco control policy 2000-2010 with the target to reduce the adult male smoking rate from $50 \%$ to $20 \%$. Global Adult Tobacco Survey (GATS) 2010 found that $47.4 \%$ (95\% CI $45.4 \%$ to $49.4 \%$ ) of Vietnamese male adults were smokers, meaning that the tobacco control target was not achieved. ${ }^{1}$ In 2013, the government adopted a new national strategy for prevention and control of tobacco's harmful effects through 2020 of the Socialist Republic of Vietnam aiming to reduce the smoking rate among adult males to $39 \%$ by $2020 .^{2}$ The GATS 2015 found that $45.3 \%(95 \%$ CI $43.1 \%$ to $47.5 \%)$ of Vietnamese male adults were smokers, meaning that the country should further reduce the male smoking rate by $14 \%$ in relative terms if they want to achieve the target. ${ }^{3}$

There are several simple, evidence-based measures to achieve this target. WHO Framework Convention on Tobacco Control (WHO FCTC) recognises tax as one of the most effective ways to reduce tobacco use, and recommends taxation to be part of any comprehensive tobacco control strategy. ${ }^{45} \mathrm{In}$ 2004, Vietnam ratified the WHO FCTC. A special consumption tax (or excise tax) on tobacco was adjusted from three different ad valorem rates $(25 \%, 45 \%$ and $65 \%)$ to a uniform ad valorem rate of $55 \%$, calculated on the factory price in January 2006. It was increased up to $65 \%$ in January 2008. Vietnam's most recent tax increases were passed by law in November 2014, and increased the rate from $65 \%$ to $70 \%$ in January 2016 , and then to $75 \%$ in January 2019. The compulsory contribution to the Tobacco Control Fund has also risen from 1\% to $2 \%$ of the taxable price between 2015 and $2019 .^{67}$

The aim of this paper is to assess what contribution these tax increases can be expected to have made to public health, particularly in relation to the national tobacco control strategy's target. The assessment can highlight areas where Vietnam may need to implement additional measures to improve these outcomes.

\section{METHODS}

\section{Data sources}

This study uses several primary data sources to create a complete baseline profile of Vietnam's cigarette market for 2015, including the rate of smoking among adults from the GATS. ${ }^{3}$ Administrative data collected by the Ministry of Finance's Tax Policy Department (TPD) on the sales volume and taxable price (sometimes referred to as the producer or ex-factory price) of around 160 brands and brand variants were combined to estimate annual tax revenue from cigarettes for 2015-2017. ${ }^{8}$ Note these estimates were calibrated to match with aggregate cigarette tax revenue data also from TPD.

The TPD and HealthBridge also undertook crosssectional retail store surveys in 2016 and 2019 to collect the retail price of brands. The survey was conducted in Hanoi and Ho Chi Minh city each year between the months of April and May. A total of 600 retail stores were investigated, with stratification according to urban and rural areas, as well as by store type. These two surveys being supplemented by brand data from two international market survey companies. ${ }^{9} 10$ 
We were able to match the retail price of 72 brands from across the price spectrum in Vietnam with their corresponding taxable price. The price of brands not observed in the survey were estimated based on the finding from our sample that the taxable prices account $40.0 \%$ (95\% CI $38.5 \%$ to $41.5 \%$ ) of the retail price $(\mathrm{p}<0.001)$. Incidentally, the distribution (wholesale and retail) margin was found to account for $25.2 \%$ (95\% CI $22.4 \%$ to $28.1 \%$ ) of the retail price of sampled brands $(\mathrm{p}<0.001)$.

After using the available data sources, it was necessary to use forecasting techniques to assess the expected impact of the tax law on the rate of smoking for 2016-2020, and on cigarette consumption and the tax revenues for 2018-2020. Macroeconomic variables, such as Vietnam's Gross Domestic Product (GDP) and the inflation rate, were taken from the International Monetary Fund's (IMF) World Economic Outlook. ${ }^{11}$

\section{Taxes and prices}

The starting point of the predictive component of our assessment is the interaction between cigarette tax and price increases. Given Vietnam's current tobacco tax system, the retail price $(R P)$ of each brand $(i)$ can be deconstructed into the following components ${ }^{12}$ :

$$
R P_{i}=D M_{i}+\left(V T_{i} \times\left(E T_{i}+T P_{i}\right)\right)+\left(\left(T C_{i}+E T_{i}\right) \times T P_{i}\right)
$$

where $(T P)$ is the taxable price, $(T C)$ is the Tobacco Control Fund compulsory contribution and (ET) is excise both of which are levied on the taxable price, (VT) is the VAT levied on the taxable price plus excise, and (DM) is the distribution margin which is not subject to indirect taxes in Vietnam. For modelling purposes, we further categorise brands into three market segments $(j)$ in the market, where economy brands are less than VND 10 000/pack, mid-price brands are between VND 10000 and 22 500/pack, and premium brands are above VND 22 500/ pack. Note these segments were defined by consensus among local partners including the Ministry of Finance, and based on price-point of key brands as well as the overall spread of retail prices in the market.

When predicting the new retail price $\left(\mathrm{RP}_{\mathrm{ii}}{ }^{*}\right)$ of brands following a tax increase, it is common to make an ex ante assumption of full tax pass-through. ${ }^{13-15}$ This essentially means that ex-factory prices are held constant. However, the experience of Vietnam from 2016 suggests that cigarette manufacturers raised their prices by more than the tax increase-a behaviour known as overshifting-with this being most evident for the premium brands. The overshifting behaviour is consistent with theory about the pricing strategies of monopolists, for example, when the environment becomes less favourable. Namely, the monopolist will tend to set retail prices much higher to maximise short-run profits, given the expectation of lower profits in the longer term. ${ }^{16}$

There are many examples of cigarette manufacturers overshifting prices in the literature, including middle-income countries like South Africa. ${ }^{17} 18$ At the same time, there is also clear evidence that tax structure can have a substantial impact on cigarette pricing, with pure ad valorem systems like Vietnam's being associated with cigarette markets that have greater price distribution and variability compared with markets with specific excise systems. ${ }^{19-21}$

Given the ex poste experience in Vietnam, the new retail price $\left(\mathrm{RP}_{\mathrm{i}}\right)$ of brands following an excise tax increase in Vietnam is calculated as:

$$
R P_{i} *=D M_{i}+\left(V T_{i} \times\left(E T_{i} *+T P_{i} *\right)\right)+\left(\left(T C_{i}+E T_{i} *\right) \times T P_{i i} *\right)
$$

where the new taxable price $\left(\mathrm{TP}_{\mathrm{ij}}{ }^{*}\right)$ for each segment is overshifted by between $5 \%$ and $15 \%$. In contrast, evidence since 2015 suggests that both the taxable and retail price of individual brands within each segment change very little, at least in the short term, without accompanying tax increases. This is also similar to the experience in China-a country with very similar characteristics to Vietnam including with respect to the cigarette market. ${ }^{18}$

\section{Consumption and use}

Our modelling employs several economic parameters when modelling the impact of tax and price increases on cigarette consumption beyond 2017. The key economic parameter here is the price elasticity of demand (PE) which measures the extent to which a real or inflation-adjusted increase in the price of cigarettes will reduce consumption (ie, total number of sticks consumed per year). For example, a price elasticity of -0.5 means that a $10 \%$ increase in the real price of cigarettes will reduce cigarette consumption by 5\%. Empirical studies in developing countries have found price elasticities that cluster around -0.5 within a range of -0.2 to $-0.8 .^{22} \mathrm{~A}$ meta-analysis of 25 empirical studies for Vietnam found that the price elasticity of demand for cigarettes is likely no higher than $-0.5 .^{23}$

Empirical studies throughout the world have also found that lower-income households tend to be more responsive to cigarette price changes. ${ }^{22}$ Recently, this characteristic of demand has been highlighted in a number of cross-sectional studies by the World Bank including for Bangladesh, Chile, Indonesia, Moldova, South Africa, Russia and Vietnam. ${ }^{24} 25$ In Vietnam, household in the middle-income deciles recorded elasticities close to -0.5 , while low and high-income households recorded elasticities above and below -0.5 , respectively. ${ }^{25}$

We have combined this evidence in our modelling approach by applying different price elasticities to each segment of the market $(-0.3$ for the premium brands, -0.5 for the mid-price brands and -0.7 for economy brands) using the following arc form:

$$
\begin{aligned}
& C C_{i} *=C C_{i}\left[1+P E_{j}\left(R P_{i} *-R P_{i}\right) /\left(R P_{i}+R P_{i} *\right)\right] / \\
& {\left[1-P E_{j}\left(R P_{i} *-R P_{i}\right) /\left(R P_{i}+R P_{i} *\right)\right]}
\end{aligned}
$$

where $\left(\mathrm{CC}_{\mathrm{i}}\right)$ is cigarette consumption by brand and $\left(\mathrm{PE}_{\mathrm{j}}\right)$ is the price elasticity for the corresponding price segment.

The second key parameter to consider is the relationship between cigarette consumption and household income, otherwise known as the income elasticity of demand. In many countries, cigarette demand functions as a normal good meaning that cigarette consumption increases as household incomes grow. The income elasticity of demand therefore tends to be positive, with evidence suggesting that it ranges between 0 and 0.6 in low-income and middle-income countries, with a similar range being reported in the past for Vietnam. ${ }^{22}$ Vietnam has experienced rapid economic growth since the early 1990s, which in turn was associated with a very rapid increase in the affordability of cigarettes. ${ }^{26}$

These factors undoubtedly contributed to the large increase in cigarette consumption as was witnessed for Vietnam during the 1990s and 2000s. Although economic growth remains sound, the affordability of cigarettes has largely stabilised since the turn of the last decade. ${ }^{26}$ Smoking prevalence, at least among males, in Vietnam is also relatively high as is the quantity of cigarettes consumed per day (an average of 13.5 and 13.7 sticks per day from GATS 2010 and 2015, respectively). ${ }^{1}$ Thus, we expect the effect size to be relatively low. We have taken 0.3 and 0.15 as 
the income elasticity of demand for premium and mid-price cigarettes in Vietnam, but did not include any effect size for economy brands as explained below:

$$
\begin{aligned}
& C C_{i} *=C C_{i}\left[1+I E_{j}(I C *-I C) /(I C+I C *)\right] / \\
& {\left[1-I E_{j}(I C *-I C) /(I C+I C *)\right]}
\end{aligned}
$$

where (IE) is the income elasticity and (IC) is per capita income growth using real GDP per capita as a proxy. ${ }^{11}$ The different elasticities are designed to reflect the impact of increased incomes on smokers choice with respect to perceived quality rather than quantity or in other words 'trading-up' to higher priced brands. It also stylistically reflects a common industry strategy of 'premiumisation' in countries like China, for example, where prices seldom increase but marketing and promotion aims to encourage smokers to trade-up.

Overall, the modelling approach combines the two price and income elasticity effects to estimate annual cigarette consumption from 2017 to 2020.

Given cigarette prices and consumption, the final component to be modelled is the rate of smoking among adults since GATS in 2015. In this respect, the price elasticity of demand for cigarettes reflects a mix of conditional demand (the intensity of smoking) and the number of smokers (ie, participation). The empirical evidence shows that about half of the reduction in cigarette consumption due to a price increase is due to a decrease in conditional demand (intensity), while the other half is due to a reduction in prevalence (ie, people quitting). ${ }^{22} 27$ Hence, the price prevalence elasticity of demand accounts for about half the decrease in cigarette consumption. ${ }^{22}{ }^{28}$ For example, a price elasticity of -0.5 for cigarettes in middleincome countries would include a price prevalence elasticity of around $-0.25 .{ }^{1822} 29$

However, our modelling of prevalence extends beyond the short term (ie, >2-3 years) so it may be appropriate to incorporate an underlying trend determinant reflecting changes in wider population norms and standards as well as the cumulative effect of past tobacco control interventions. In this respect, the aim is delineate the impact of tax increases since 2015 from any underlying trend, while also incorporating all elements into our modelling of smoking prevalence in 2020 relative to the target set by the governments national tobacco control strategy.

The two latest GATS studies are indicative of a decrease in Vietnam, with the rate of smoking falling from $23.8 \%$ (95\% CI $22.7 \%$ to $24.9 \%$ ) to $22.5 \%$ (95\% CI $21.3 \%$ to $23.8 \%$ ) between 2010 and 2015, including a significant decline in cigarette smoking $(\mathrm{p}<0.05) .{ }^{13} \mathrm{~A}$ recent WHO study applies Bayesian meta-regression trend analysis to project the rate of tobacco use in WHO regions, and projects that use in the whole Western Pacific Region (WPR) will decrease in relative terms by $-0.6 \%$ per annum between 2015 and $2020 .^{30}$ We use the wider WPR as a reference for Vietnam, which at the same time tends to avoid the potential for country specific interventions to overly influence our modelling of this trend.

We incorporate an underlying trend component into our modelling of prevalence using the following:

$$
P R_{i j} *=P R_{i j}+\left[P R_{i j} \times\left(1+\left(\Delta C C_{i j} \times 0.5\right)+\Delta T P_{i j}\right)\right]
$$

where the new prevalence rate of smoking $\left(P R_{i i} *\right)$ is calculated as half the change in cigarette consumption $(\triangle C C)$, with this being a combination of the price and income effects, plus the underlying prevalence trend $\left(\Delta T P_{i j}\right)$ ranging between -0.3 and -0.9 per year as described above. ${ }^{30}$

Finally, we conduct further sensitivity tests by altering the price and income elasticities by $\pm 50 \%$, respectively.

\begin{tabular}{|c|c|c|c|c|c|}
\hline & & 2015 & 2020 & Change & $\%$ change \\
\hline \multirow{4}{*}{$\begin{array}{l}\text { Retail price ( } ₫ 000 / \\
\text { pack) }\end{array}$} & Premium & 22.3 & 29.2 & 6.9 & 31 \\
\hline & Mid-price & 15.2 & 18.5 & 3.3 & 22 \\
\hline & Economy & 7.4 & 9.3 & 2.0 & 27 \\
\hline & Average & 12.1 & 14.0 & 1.9 & 16 \\
\hline \multirow{4}{*}{$\begin{array}{l}\text { Retail sales } \\
\text { (Billion packs) }\end{array}$} & Premium & 288 & 287 & -1 & 0 \\
\hline & Mid-price & 1839 & 1297 & -542 & -29 \\
\hline & Economy & 1812 & 2156 & 344 & 19 \\
\hline & Total & 3939 & 3740 & -199 & -5 \\
\hline \multirow{4}{*}{$\begin{array}{l}\text { Tax revenue } \\
\text { (Billion VND) }\end{array}$} & Premium & 2173 & 3086 & 913 & 42 \\
\hline & Mid-price & 9215 & 8639 & -576 & -6 \\
\hline & Economy & 4541 & 7480 & 2939 & 65 \\
\hline & Total & 15929 & 19206 & 3277 & 21 \\
\hline \multirow{3}{*}{$\begin{array}{l}\text { Smoking } \\
\text { Indicators }\end{array}$} & Smokers (000s) & 15602 & 15465 & 137 & -2 \\
\hline & Smoking rate (\%) & 22.5 & 21.3 & -1.2 & -5 \\
\hline & Affordability ${ }^{*}(\%)$ & 3.9 & 3.4 & -0.4 & -12 \\
\hline
\end{tabular}

Table 1 Impact of Vietnam's current tobacco tax law from 2015 to 2020

*Percantage of GDP per capita needed to purchase 100 packs.

GDP, gross domestic product.

\section{RESULTS}

Table 1 presents the findings of our assessment with retail prices and tax revenues reported in inflation-adjusted terms at 2015 constant prices. The average retail price of cigarettes increased by $₫ 1900 /$ pack or by $16 \%$ (range 14\%-18\%) between 2015 and 2020. There is some variation between segments with the price of premium cigarettes increasing by about $31 \%$. As discussed, these retail price increases reflect, in part, the strategy of cigarette manufacturers to over-shift the tax increase.

The number of cigarette packs consumed in 2020 is estimated to decrease by $5 \%$ (range $4.5 \%-5.5 \%$ ) on 2015, representing about 200 million fewer packs sold annually. Figure 1 shows cigarette consumption over a longer timeframe since $1990 .{ }^{9}$ Vietnam adjusted excise taxes twice prior to the current excise tax law. In 2006, the government merged three tiers of ad valorem excise into a single rate of $55 \%$ on the taxable price. In 2008 , excise was increased to $65 \%$ of the taxable price. Cigarette consumption initially decreased by about $3 \%$ after each of these episodes, but recovered shortly thereafter. Our modelling suggests a similar pattern, with cigarette consumption estimated to decrease by about $4 \%$ in both 2016 and 2019 .

Table 1 highlights what appears to be a significant degree of substitution between the segments, namely from mid-price to economy brands. This suggests that smokers responded to price increases in part by 'trading-down' to cheaper brands. This substitution effect is a common feature of markets like Vietnam,

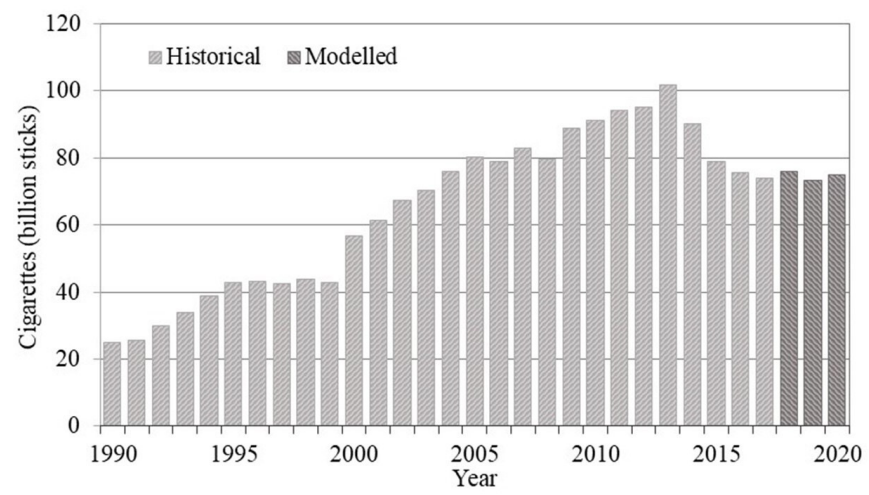

Figure 1 Cigarette retail sales volumes in Vietnam, 1990-2020. 
where the excise is purely ad valorem and there is a wide price spread on offer. It is also a major concern for tobacco control, because the ability of smokers to trade-down can weaken their incentive to quit smoking. However, we should exercise some caution with this finding as there are some data limitations, and brand-level information can reflect to a certain extent manufacturer marketing strategies, particularly in monopolistic markets.

Table 1 shows that the prevalence rate of smoking among all adults in Vietnam is projected to decrease by $1.2 \%$ from $22.5 \%$ (95\% CI $21.3 \%$ to $23.8 \%$ ) in 2015 to $21.3 \%$ (range $20.9 \%$ $21.7 \%)$ in 2020 . This would represent a $5 \%(3 \%-7 \%)$ relative decline in the rate smoking, compared with the $14 \%$ relative decrease envisaged under the national tobacco control strategy. For example, the strategy aims to reduce the rate of smoking among males to $39 \%$ by 2020 , while our modelling suggests a decrease to $42.8 \%(41.2 \%-43.6 \%)$. Overall, the decrease in Vietnam's smoking rate is expected to be relatively modest through to 2020.

We assess the contribution that excise tax increases have made several ways. First, the trend prevalence effect alone suggests that the rate of smoking in Vietnam should have fallen to about $21.8 \%$ compared with our assessment of $21.3 \%$. On this basis, excise tax increases suppressed the smoking rate by a further $0.6 \%$. Second, we apply a counterfactual scenario in which taxes remain unchanged at 2016 levels. On this basis, smoking prevalence in Vietnam would have fallen to about $21.9 \%$. On this basis, excise rate increases also suppressed the smoking rate by about $0.6 \%$, with both comparisons suggesting that excise tax increases accounted for about half of the overall 1.2\% expected decline in smoking.

Table 1 also presents the modelled outcome for total tax revenues from cigarettes. Tax revenues are projected to increase by $21 \%(19 \%-23 \%)$ on 2015 , reflecting an extra $₫ 3300$ billion in revenues for the government each year. The current excise tax law is expected, therefore, to have contributed measurably to the government's revenue mobilisation efforts. However, to put this in perspective, the IMF projects government revenue in Vietnam to increase by $34 \%$ in inflation-adjusted terms over the same period, thus excise revenue growth from cigarettes may not have kept pace with total government revenue growth. ${ }^{11}$

\section{DISCUSSION}

Our study finds that Vietnam's excise tax law, with its pure ad valorem system, is expected to have only a modest impact on the smoking rate. This is consistent with historical trends in cigarette consumption, where the impact of tax increases has not been sustained due, in part, to strong household income growth. Furthermore, our findings highlight the problem of 'tradingdown', which is often associated with ad valorem systems and markets with wide price spreads between cheap and premium brands like in Vietnam.

In many countries—like China, India and Vietnam—cigarette manufacturers maximise profits by offering brands and variants at different price points, which helps to support trading-up or down by smokers. This includes offering very cheap-priced brands that encourage price sensitive consumers (ie, youth and the poor) to take-up smoking. Data compiled by WHO suggests that Vietnam has among the cheapest cigarette prices and widest price spreads among countries throughout the world. ${ }^{12}$ Even after the latest tax increase in 2019, the share of tax in the retail price of cigarettes in Vietnam is estimated in this paper to average just $36.6 \%$ compared with $58.3 \%$ across all middleincome countries in $2018 .^{12}$
Historically, many countries have used tobacco taxation as a revenue generator and so incremental increases in excise rates were the norm, and other concerns such as pricing played little role in policy design. Most countries have now recognised the importance of tobacco taxation as a public health measure. Vietnam, for example, has set a robust prevalence reduction target in its national tobacco control strategy, and it is now an opportune time to consider what kind of tobacco tax system would best serve Vietnam's public health interests while also generating tax revenue.

Internationally, there is consensus that specific or mixed excise systems lead to better outcomes-in terms of higher cigarette prices and tax yields-than pure ad valorem systems like Vietnam's. ${ }^{51219}$ These systems also raise the price of cheapest brands the most thus, helping to prevent vulnerable groups like the young and the poor from taking-up smoking. ${ }^{19}{ }^{25}$ Tax structure can have a substantial impact on pricing, with pure ad valorem systems being associated with cigarette markets that have greater price distribution and variability, while experience in countries like Brazil, Mexico and across the Europe Union has shown that mixed excise systems can reduce consumption by raising prices and reducing overall price variability. ${ }^{18} 193132$

In 2019, the Ministry of Finance included a mixed excise system as an option for cigarettes during public consultations on excise tax law reform. These options have not yet been formally placed before the National Assembly. Nonetheless, the tobacco control community would certainly support the introduction of

\section{What this paper adds}

What is already known on this subject

- The government of Vietnam has made several commitments to reduce tobacco use, including the national strategy for the prevention and control of tobacco's harmful effects through 2020 which aims to reduce the smoking rate among male adults to $39 \%$. Tobacco taxation has been one of the main tobacco control policies to be implemented over this period, with the excise tax law mandating tax increases in 2016 and 2019. This paper aims to assess what contribution these tax increases can be expected to have made to the national tobacco control strategy's target.

What important gaps in knowledge exist on this topic

- There is a good understanding about the impact of Vietnam's 2015 tobacco tax increase on cigarette retail prices, consumption, and tax revenues via administrative datasets and surveys. However, the impact of subsequent tax and price increases is not documented. Also, there is no information about any changes on the rate of smoking since 2015, with this being most important for Vietnam's national tobacco control strategy.

\section{What this paper adds}

- This study uses a mix of administrative data and predictive modelling techniques to assess the expected impact of tax and price increases on cigarette tax revenues, consumption and the rate of smoking from 2015 to 2020 . We find that the excise tax law, with its pure ad valorem system, is expected to have only a modest impact on the rate of smoking. We recommend the introduction of a mixed excise system, with heavy reliance on the specific component to raise the price of cigarettes more significantly. 
a mixed excise system, especially with a high-specific excise to help achieve public health objectives.

\section{CONCLUSION}

The excise tax law 2015-2020 is expected to have had only a modest impact on the rate of smoking in Vietnam, though it has generated tax revenues. If Vietnam is to achieve its tobacco control targets, the government should implement a mixed excise system on cigarettes, with heavy reliance on the specific component to raise the price of cigarettes more significantly.

Contributors MG designed the study, collected secondary data, undertook the analysis and drafted the text. LTT, SD and LNT collected primary data, supported the analysis and contributed to drafting the text. RT, JP and KP contributed to the design of the study and to the drafting of the text.

Funding The authors have not declared a specific grant for this research from any funding agency in the public, commercial or not-for-profit sectors

Disclaimer The authors alone are responsible for the views expressed in this article and they do not necessarily represent the views, decisions or policies of the institutions with which they are affiliated.

Competing interests None declared.

Patient consent for publication Not required.

Provenance and peer review Not commissioned; externally peer reviewed.

Data availability statement All data relevant to the study are included in the article or uploaded as ONLINE supplementaL information. All data relevant to the study are included in the article.

Open access This is an open access article distributed in accordance with the Creative Commons Attribution Non Commercial (CC BY-NC 4.0) license, which permits others to distribute, remix, adapt, build upon this work non-commercially, and license their derivative works on different terms, provided the original work is properly cited, appropriate credit is given, any changes made indicated, and the use is non-commercial. See: http://creativecommons.org/licenses/by-nc/4.0/.

ORCID iD

Mark Goodchild http://orcid.org/0000-0002-1826-1343

\section{REFERENCES}

1 WHO. Global adult tobacco comparison factsheet, Vietnam 2020 \& 2015. Geneva: World Health Organization, 2016. https://www.who.int/tobacco/surveillance/survey/ gats/VN2015_FactSheet_Comparison_E_Oct2016.pdf?ua=1

2 Prime Ministerial Decision No. 229/QD-TTG, the National strategy on the prevention and control of tobacco's harmful effects through 2020, 2020. Available: http://www. chinhphu.vn/portal/page/portal/English/strategies/strategiesdetails? categoryld=30\& articleld $=10055285$ [Accessed 3 Mar 2020]

3 Van Minh H, Giang KB, Ngoc NB, et al. Prevalence of tobacco smoking in Vietnam: findings from the global adult tobacco survey 2015. Int J Public Health 2017;62:121-9.

4 WHO. Who framework convention on tobacco control. Geneva: World Health Organization, 2003.

5 WHO. Guidelines for implementation of article 6 of the who FCTC. Geneva: World Health Organization, 2014.

6 WHO. Tobacco taxes in Vietnam: questions and answers. Hanoi: World Health Organization Representative Office for Vietnam, 2018.
7 World Bank. Vietnam: tobacco control legislation, use, and taxation. Washington DC, world bank group, 2019

8 Tax Policy Department. Internal communications with the tobacco control fund and the Ministry of industry and Commerce.

9 Euromonitor international. London. Available: http://www.euromonitor.com

10 Globaldata. London. Available: http://.GlobalData.com

11 IMF world economic outlook April 2019 database.

12 WHO. Who report on the global tobacco epidemic, 2019. Geneva: World Health Organization, 2019

13 Goodchild M, Perucic A-M, Nargis N. Modelling the impact of raising tobacco taxes on public health and finance. Bull World Health Organ 2016;94:250-7.

14 Goodchild M, Sandoval RC, Belausteguigoitia I. Generating revenue by raising tobacco taxes in Latin America and the Caribbean. Rev Panam Salud Publica 2017:41:e151.

15 van Walbeek C. A simulation model to predict the fiscal and public health impact of a change in cigarette excise taxes. Tob Control 2010;19:31-6.

16 Becker GS, Grossman M, Murphy KM. An empirical analysis of cigarette addiction. Am Econ Rev 1994:84:396-418.

17 Linegar DJ, van Walbeek C. The effect of excise tax increases on cigarette prices in South Africa. Tob Control 2018:27:65-71.

18 Goodchild M, Zheng R. Early assessment of China's 2015 tobacco Tax increase. Bull World Health Organ 2018;96:506-12.

19 Shang C, Chaloupka FJ, Fong GT, et al. The association between Tax structure and cigarette price variability: findings from the ITC project. Tob Control 2015;24 Suppl 3:iii88-93.

20 Shang C, Chaloupka FJ, Zahra N, et al. The distribution of cigarette prices under different Tax structures: findings from the International tobacco control policy evaluation (ITC) project. Tob Control 2014;23 Suppl 1:i23-9.

21 Liber AC, Ross H, Ratanachena S, et al. Cigarette price level and variation in five Southeast Asian countries. Tob Control 2015;24:e137-41.

22 National Cancer Institute. The economics of tobacco and tobacco control. National cancer Institute tobacco control monograph 21. NIH publication No. 16-CA-8029A. Bethesda, MD: U.S. Department of Health and Human Services, National Institutes of Health, National Cancer Institute, 2016

23 Guindon GE, Hien NTT, Kinh HV, et al. Tobacco taxation in Vietnam. Paris: International Union Against Tuberculosis and Lung Disease, 2010.

24 Fuchs, Icaza \& Paz. Distributional effects of tobacco taxation - a comparative analysis. Washington DC: World Bank, 2019.

25 Fuchs \& Icaza. The distributional effects of increases taxes on tobacco in Vietnam. Washington DC: World Bank, 2019.

26 Blecher E, TT L, An N. Tobacconomics policy note: affordability of cigarettes in Vietnam. Chicago, IK: Tobaccoomics, Health Policy Center, Institute for Health Research and Policy, University of Illinois at Chicago, 2019.

27 IARC. Effectiveness of Tax and price policies for tobacco control. IARC handbooks of cancer prevention: tobacco control. 14. International Agency for Research on Cancer: Lyon, 2011.

28 Levy DT, Tam J, Kuo C, et al. The impact of implementing tobacco control policies: the 2017 tobacco control policy scorecard. J Public Health Manag Pract 2018;24:448-57.

29 Levy DT, Ellis JA, Mays D, et al. Smoking-Related deaths averted due to three years of policy progress. Bull World Health Organ 2013;91:509-18.

30 WHO. WHO global report on trends in prevalence of tobacco use 2000-2025. third edition. Geneva:World Health Organization, 2019. https://apps.who.int/iris/bitstream/ handle/10665/330221/9789240000032-eng.pdf?ua=1

31 Shang C, Lee HM, Chaloupka FJ, et al. Association between Tax structure and cigarette consumption: findings from the International tobacco control policy evaluation (ITC) project. Tob Control 2019;28:s31-6.

32 Delipalla S, O'Donnell O. The Comparison Between Ad Valorem and Specific Taxation under Imperfect Competition: Evidence from the European Cigarette Industry," Studies in Economics 9802, School of Economics, University of Kent 1998 